\title{
La Etapa Jordana (1942-1944) *
}

\author{
JAVIER TUSELL
}

Sería incorrecto pretender que la actitud española ante la segunda guerra mundial se pueda resumir en las dos posturas, sucesivas y contrarias, de los ministros de Asuntos Exteriores, Ramón Serrano Súñer y Francisco Gómez Jordana; ello equivaldría a pretender que la posición española pudo adoptarse con independencia del desarrollo de la propia guerra o que nada contó la posición de Franco. En realidad esa actitud sólo puede entenderse teniendo muy en cuenta las alternativas del conflicto y tiene una línea vertebral de continuidad, que es la que le da la propia personalidad de Franco, quien fue siempre no sólo el principal factor de decisión en el seno de su régimen sino, en última instancia, el único. Sin embargo esto no quiere decir que los dos ministros de Asuntos Exteriores carecieran de una posición propia, particular y distinta respecto de las materias de su competencia y más concretamente de la actitud de España ante el conflicto mundial. La diferencia fue real y resultaba muy expresiva del régimen de Franco que, si, por un lado, tenía un componente, fascista o fascistizado, inequívoco, por otro lado, desde un principio, también tuvo entre sus dirigentes a sectores simplemente conservadores, tradicionalistas y católicos. Quizá el hecho de que naciera

\footnotetext{
* En este artículo se ha procurado sobre todo utilizar la abundante domentación inédita que sólo recientemente ha sido utilizada por los historiadores españoles para conocer la posición española ante la segunda guerra mundial. Las siglas más importantes utilizadas son las siguientes:
}

ASMAE: Archivio Storico del Ministeri degli Affari Esteri (Roma).

AJE: Archivo de la Jefatura del Estado.

AGA, AE: Archivo General de la Administración, Asuntos Exteriores.

AMAE: Archivo del Ministerio de Asuntos Exteriores.

STAP: St' Antony's Papers (documentos de la República Social Italiana) (Oxford).

FO: Foreign Office. 
de una guerra civil, a diferencia de lo sucedido en Italia o Alemania, obligaba a tener en cuenta a un sector más amplio de la población que el partido fascista propiamente dicho.

Francisco Gómez Jordana, conde de Jordana, era muy representativo de esos sectores no fascistas del régimen de Franco. Militar africanista, durante la dictadura de Primo de Rivera (1923-1930) había destacado como organizador y administrador; en realidad él no participó en la conspiración que llevó al poder a Primo de Rivera pero este le obligó a formar parte del Directorio militar que gobernó hasta 1925. Fue, en este período, principal responsable de la acción en Marruecos, participando en las negociaciones con Francia y asumiendo después de la pacificación de la rebelión rifeña el cargo de Alto Comisario en Marruecos. La proclamación de la República detuvo su carrera militar y le supuso un proceso responsabilista por su colaboración anterior con Primo de Rivera. Cuando estalló la Guerra Civil (en cuya conspiración tampoco él había tomado parte) fue llamado por los generales sublevados pero no para el mando de tropas sino para tareas organizativas en la retaguardia. En junio de 1937 se hizo cargo de la presidencia de la Junta Técnica de Estado, el primer germen de administración de la España franquista. De allí pasó a la vicepresidencia y a la cartera de Asuntos Exteriores cuando, en las primeras semanas de 1938, Franco creó su primer Gobierno; es muy significativo que, cuando fue nombrado para ese cargo, una de las primeras felicitaciones procediera del antiguo monarca, Alfonso XIII. Representaba Jordana, en efecto, una postura de tradicionalismo conservador, mucho más vinculada al catolicismo y a los sectores más de derecha de las democracias, que al fascismo italiano o alemán. De hecho esta actitud se demostrará en el transcurso de la guerra civil por lo menos en dos ocasiones cruciales: la crisis checoslovaca (septiembre-octubre de 1938) y durante la fase final del conflicto en que ya se anunciaba el alienamiento español respecto del nuevo escenario internacional. Durante el peor momento de la crisis checa Jordana, consciente de que Francia quería tener seguridades de la neutralidad española, se decantó hacia una pública proclamación de ésta que irritó profundamente a Italia, la cual estaba prestando a Franco una ayuda militar importantísima. En los primeros meses de 1939 Jordana se fue inclinando, de nuevo, hacia una posición neutralista, procurando el restablecimiento de las relaciones con Francia, que consiguió. Sin embargo ya entonces la estrella ascendiente del régimen de Franco era Ramón Serrano Súñer, que ocupaba el Ministerio de la Gobernación pero cuya influencia abarcaba ya la totalidad de las esferas de la vida política española. 
Así se demostró con su viaje a Italia en mayo-junio de 1939 durante el cual Serrano anudó una relación de amistad con Ciano que fue duradera y que, por su puesto, tenía componentes políticos, suponiendo la voluntad de «fascistizar» el régimen español y de alinearlo con el Eje, principalmente con Italia. El primer paso en este sentido fue el viaje del propio Ciano a España en julio de 1939, de cuya organización estuvo marginado Jordana por completo. Este hecho demostraba una situación política de crisis que, finalmente, tuvo su desenlace a comienzos del mes de agosto siguiente. Serrano alcanzó en este momento una posición predominante que, con alternativas, no perdería hasta bien entrado el año 1941 y que sólo se desvaneció definitivamente en $1942{ }^{1}$. Durante este período Jordana, nombrado Presidente del Consejo de Estado, un puesto consultivo y honorífico pero carente de verdadero poder, observó con preocupación el rumbo de la política exterior española: confiaba en que Franco no decidiría la intervención en el conflicto europeo, de la que él era decidido opositor, pero no tenía la menor seguridad de que Serrano Súñer pensara en términos semejantes y juzgaba que las circunstancias podían convertirse en una verdadera tentación para los dirigentes españoles. Su condición de buen administrador, la política que había ejecutado en su ministerio anterior y su moderación le habían convertido en un candidato evidente del sector militar en el seno del régimen de Franco para llegar de nuevo a un puesto de primera importancia en su seno.

Para explicar la decisión de Franco de volverle a nombrar ministro de Asuntos Exteriores hay que hacer referencia a la evolución de la política interior española, mucho más que a la exterior. En realidad a partir de los primeros meses de 1941 las posibilidades de que España participara en la guerra europea se fueron desvaneciendo; la razón estriba en que Hitler sólo tuvo un interés episódico en el Mediterráneo y la ofensiva en contra de Rusia vedaba cualquier posibilidad de emprender otra semejante para lograr la ocupación de Gibraltar. Mientras tanto, en España, que había estado dispuesta a participar en el conflicto a cambio de una expansión territorial a la que no estaba dispuesto Hitler, se producía una lucha sorda pero durísima entre los dos elementos fundamentales del régimen: los falangistas y los militares. Los primeros, jóvenes y revolucionarios, habían contado con la fuerza política de Serrano Súñer para pretender transformar el régimen en sentido fascista; obviamente en

${ }^{1}$ Para los antecedentes de la gestión de Jordana véase TusELL-GARCIA QUEIPO DE LLANO, Franco y Mussolini..., 1-50. Jordana dejó unas memorias sobre su acción en los asuntos marroquíes, titulada "La tramoya de nuestra actuación en Marruecos», 1976. 
sus planes estaba una intervención en la guerra a favor del Eje. En cuanto a los militares, conservadores y monárquicos, eran conscientes de la impotencia del Ejército español, despreciaban a los falangistas y a Serrano, al que consideraban megalómano, y tan sólo hubieran estado dispuestos a una intervención en la guerra con absolutas seguridades de que las ventajas serían muchas y el riesgo mínimo. Franco jugaba con ambos sectores: era prudente y sabía la posición de sus compañeros de armas pero, al mismo tiempo, utilizaba muy a menudo un lenguaje falangista, aunque sólo muy pocos otros militares (Yagüe, Muñoz Grandes) lo hicieran también.

El enfrentamiento entre estos dos sectores llegó a producir, por vez primera y casi única durante el régimen de Franco, un derramamiento de sangre que demostraba el grado de violencia al que se había llegado. EI 16 de agosto de 1942, a la salida de una ceremonia religiosa organizada por los carlistas, en Begoña y presidida por el ministro del Ejército, general Varela, fue lanzada una bomba por un grupo de falangistas; no fue propiamente un atentado sino el producto de la tensión acumulada durante meses. Lo sucedido, sin embargo, obligaba a Franco a resolver esa situación de tensión existente. El general Varela protestó indignadamente en contra de Franco y eso le obligaba a éste a sustituirlo, pero, con un mecanismo compensatorio muy característico de Franco, esa medida tenia que suponer también otra semejante respecto del sector falangista: uno de los dos detenidos por haber lanzado la bomba fue ejecutado pero, sobre todo, Serrano Súñer, que había sido su valedor, fue relevado de su puesto. En realidad había venido perdiendo influencia desde hacía tiempo e incluso se había hablado en meses anteriores de la posibilidad de que fuera sustituido. A la altura de 1942, sobre todo, había perdido a los ojos de Franco, el papel que le había correspondido originariamente como medio de comunicación con la Falange, al aparecer otros falangistas que, teniendo influencia en este sector político, estaban sometidos sumisamente al Jefe del Estado.

La crisis del 3 de septiembre de 1942 tuvo, por tanto, un origen puramente interno y no suponía, en principio, un giro en la política exterior; incluso antes de que Franco se decidiera a entregar la responsabilidad, en esta materia, a Jordana pensó en otras posibilidades o en destinarle al Ministerio del Ejército. Sin embargo a partir de este momento había quedado bien claro que el componente militar del régimen predominaba sobre el falangista; ningún dirigente de Falange llegó a tener nunca un poder semejante al de Serrano Súñer, ni tampoco su inteligencia. Dada la actitud de los militares respecto de la guerra mundial 
las posibilidades de intervención española en el conflicto se reducían a una intervención aliada o unas promesas seguras en el caso de que la victoria del Eje pareciera inminente. En general los aliados recibieron bien el cambio producido en España; los países del Eje, por su parte, dada la marginalidad de España y las luchas internas desarrolladas hasta el momento, tampoco parecieron tener mucho en contra de lo sucedido, pues, a fin de cuentas, también en el Este de Europa Hitler se apoyó más en regímenes militares que en otros homologados con el fascismo ${ }^{2}$.

Sin embargo la propia presencia en el Ministerio de Asuntos Exteriores de Jordana necesariamente había de tener como implicación un giro en la política exterior española en cuanto que el nuevo ministro tenía unos planteamientos en esta materia distintos de los de su predecesor. Para entender hasta qué punto este cambio podía afectar al contenido de la política española hay que tener en cuenta la peculiaridad de la relación entre Franco y sus ministros. El bando que había triunfado en la guerra civil era, por lo menos, relativamente plural y, como tal, se mantenía en unión gracias al arbitraje de Franco; ésto tenía como consecuencia que un ministro podía no ser absolutamente idéntico en sus concepciones al resto de sus compañeros de gabinete $y$, por lo tanto, podía tener un grado de autonomía relativamente alto. Es obvio que estaba sometido, en los planteamientos más generales, a Franco pero también que podía matizar de manera sustancial la política del dictador y hacerlo además impulsando algún cambio en ella, en especial cuando se veía favorecido por las circunstancias. Esa fue la relación entre Jordana y Franco. El primero, a diferencia de Serrano, no tenía ambiciones políticas de carácter general ni se había enzarzado en una lucha por el poder como aquél; sobre su fidelidad no pudo tener la menor duda Franco. Al mismo tiempo, sin embargo, fomentó la marcha hacia la neutralidad de España que se vio favorecida no sólo por su gestión sino por el propio desarrollo de la segunda guerra mundial.

Un buen ejemplo de esta relación y del cambio que, poco a poco, fue produciendo en la política española lo tenemos en lo sucedido en las primeras semanas de estancia al frente del Ministerio. Jordana dio seguridades a los representantes italianos de que él pretendía mantener unas relaciones muy estrechas con el fascismo, hasta el punto que Mussolini respondió agradeciendo esta declaración. Sin embargo unos días después, el 22 de septiembre, después de un consejo de Ministros que duró

\footnotetext{
2 Tusell-García QueIPo de Llano, Franco y Mussolini..., 168-170.
} 
cuatro días y que parece haber servido para que el nuevo gabinete discutiera la situación española, se hizo pública una nota que permitía apreciar ya un cierto cambio en la posición española. Ahora no se hacía alusión a la "no-beligerancia» que hubiera debido haber servido, en otro tiempo, para mostrar la vinculación con el Eje; por el contrario, la política exterior española sería la continuidad de la que había existido durante los seis años anteriores, es decir, no sólo la etapa de Serrano Súñer, sino también la de un Jordana que no había dudado en proclamarse neutral en octubre de 1938, durante la crisis de Munich. España se manifestaba anticomunista, pero las alusiones de otro tiempo al Eje eran sustituidas ahora por una voluntad de acercamiento a Portugal e Iberoamérica, sin duda mucho menos comprometida ${ }^{3}$. Además, esta nueva orientación de la política exterior fue ratificada en la primera ocasión en que fue posible: con ocasión del 12 de octubre Jordana hizo declaraciones en idéntico sentido. España se ocuparía ahora mismo de sus problemas y los de su pasado americano y no de la contienda europea.

Todo ello, sin embargo, hubiera podido quedar en absolutamente nada, de no ser por el desembarco aliado en el Norte de África. Una prueba complementaria de hasta qué punto había sido estrecha hasta el momento la relación entre España y el Eje es que hubo autoridades españolas que informaron a las potencias del Eje de la concentración de la flota aliąda en Gibraltar que iba a proteger dicha operación. Los aliados no pensaron entonces seriamente en invadir España: sus únicos planes estratégicos consistieron en preparar una reacción y, por lo tanto, una ocupación de España en el caso de que ésta se inclinara por el Eje o se produjera la invasión alemana de España. Los embajadores británico y norteamericano visitaron, a hora intempestiva, al ministro español para entregarle una nota en la que daban seguridades de que el desembarco no se dirigía contra España. Por su parte las autoridades españolas aceptaron esta explicación aunque a las del Eje les dijeron que no concedían demasiado valor a las promesas aliadas y les pidieron armas para fortalecer la posible necesidad de resistencia ante una eventual invasión ${ }^{4}$. El mayor temor de Jordana, una vez recibidas las seguridades aliadas, derivaba de la posibilidad de un contragolpe del Eje del que España fuera la víctima. Sin embargo esta posibilidad desapareció del horizonte a mediados de noviembre ${ }^{5}$.

${ }^{3}$ El telegrama de Mussolini en ASMAE, 10-IX-1942; ABC, 22-IX-1942.

4 P. SANCHEZ GIJON, La planificación militar británica..., 184-89 y 273-74; también Frus, 1942, III, 302-308.

${ }^{5}$ Diario de Jordana, 1 a $16-\mathrm{XI}-1942$. 
En las semanas finales de 1942, una combinación nacida de la evolución de la guerra y del cambio ministerial exigió una redefinición de la posición española que se concretó en diversos documentos que, sin embargo, no se hicieron públicos. El secretario general del partido, Arresse, dirigió a los falangistas un documento secreto en el que dejó clara la identificación de aquél con las «posiciones antidemocráticas» así como su voluntad de expansión en el Norte de África, pero, al mismo tiempo, exigió una «fe cerrada» en Franco y una disciplina que evitara decisiones poco meditadas. Pero Arresse no fue nunca el principal consejero de Franco y este documento en realidad no demuestra sino la proclividad falangista y el deseo de controlarla desde el poder. Quien sería principal consejero de Franco era ya Luis Carrero Blanco, que ocupaba la subsecretaría de la Presidencia y redactó un informe al final del año a Franco sobre la situación española y la guerra mundial. Para Carrero era necesario, sobre todo, impedir la expansión comunista en Europa y eso sólo se lograría consiguiendo que la Gran Bretaña acabara pactando con Alemania; si hubiera tenido España fuerza suficiente habría de haberse alineado con Alemania para concluir con Rusia, pero eso no era posible. Un tercer documento, también surgido de las áreas gubernamentales españolas, demostraba una voluntad más neutralista: era el del ministro de Asuntos Exteriores, Jordana, dando instrucciones al embajador español en Londres. Contradiciendo lo que hasta entonces había sido la política de Serrano Súñer, Jordana aseguró que «la nuestra no es la prebeligerancia de Italia, sino un sincero y decidido apartamiento de la beligerancia" y que, además, quería llegar a una mejora de las relaciones con los paises anglosajones. España, en definitiva, estaba en contra del comunismo pero no a favor del Eje y sólo entraría en la guerra en el caso de que violara su territorio nacional uno de los contendientes ${ }^{6}$. Como se ve estas tres posiciones coinciden en el alejamiento de una expectativa de alineamiento bélico pero difieren en muchos aspectos, mereciendo tan sólo la de Jordana el calificativo de neutra. Franco, por el momento, no parece haberse decantado ni en un sentido ni en otro. Sus declaraciones de finales del año 1942 tenían un contenido próximo a la Falange, pero probablemente las hacía por temor a que este sector se sintiera movido a la acción; al mismo tiempo remodeló las supremas responsabilidades militares marginando a militares monárquicos o disminuyendo su poder de manera que no pudiera temer tampoco desde este lado.

\footnotetext{
${ }^{6}$ ASMAE, busta 62, texto de Arresse del 12-XI-1942; Carrero, 18-XII-1942, AJE n. 2. Jordana 27-XI-1942, AMAE, 1371/3B.
} 
Obviamente era al ministro de Asuntos Exteriores al que le correspondía desempeñar un papel más importante en estas circunstancias. Las aprovechó en un viaje a Portugal en que se entrevistó con Salazar y procuró identificarse con la actitud de éste ante el conflicto; lo hizo, además, en buena medida por propia iniciativa sin consultar a Franco el contenido de sus declaraciones. Éstas consistieron en afirmar que la $\mathrm{Pe}$ nínsula era "una región serena» que pretendía permanecer alejada del conflicto y colaborar a la creación de un nuevo orden internacional, una vez conseguida la paz ${ }^{7}$. En relación con esta postura neutral y fundamentada en los principios católicos en los que coincidían ambos regímenes habría que hacer mención del acercamiento intentado a lo largo de los primeros meses de 1943 de la España de Franco hacia el Vaticano con el que había existido, sin embargo, una fuerte tensión en la etapa de Serrano, en especial durante los primeros meses de 1941. Ahora, en 1943, Franco llegó a escribir al Papa una carta en que atribuía al «judaismo» una actitud anticatólica como consecuencia de una supuesta comunicación secreta entre Roosvelt y Stalin que había llegado a su conocimiento $^{8}$. Probablemente Franco pensaba que si se podía lograr atraer a Alemania y Gran Bretaña a un frente común antisoviético era a través de la intervención del Vaticano y con un sentido europeo que quitara protagonismo tanto a los Estados Unidos como a la URSS.

En esos primeros meses de 1943 no hubo ningún peligro de que la España de Franco se decantara a favor del Eje, de quien había solicitado ayuda militar, obteniéndola de Alemania, pero tan sólo ante la eventualidad de tener que defender su territorio nacional. A diferencia de lo que sucedió en 1941 cuando Mussolini, en la entrevista de Bordighera, mostró, en la práctica, un interés muy relativo en la intervención española, ahora el dirigente fascista estaba muy deseoso de que Franco definitivamente se decantara a favor del Eje. Creía así poder atraer a los alemanes a una estrategia mediterránea que le diera alguna posibilidad de supervivencia cuando su situación resultaba cada vez más difícil. No consiguió, sin embargo, convencer a Hitler ni lo hubiera logrado con los españoles en el caso de que se lo hubiera propuesto. Cuando el Duce envió en la primavera de 1943 a España un nuevo embajador, le dio, de manera titubeante y confusa, la misión de tantear alguna posibilidad de contacto con los aliados ${ }^{9}$.

\footnotetext{
7 Ya, 19 y 20-XII-1942; Diario de Jordana, 18 a 21-XII-1942.

${ }^{8}$ Franco, IV-1943, AMAE 1371/3C.
} 
Pero si España no estaba dispuesta a intervenir en la guerra y además ésta era la postura de todos los sectores políticos del régimen de Franco, vistas las circunstancias, al mismo tiempo las diferencias internas, derivadas del mayor o menor grado de simpatía por el Eje permanecian en el seno de los dirigentes de la dictadura española. Así, en enero de 1943, Arrese, como secretario general del Movimiento, hizo un viaje a Alemania en donde se expresó en términos tan favorables al Eje que motivaron la dimisión del Ministro de Asuntos Exteriores. Fue ésta tan sólo la primera de las dimisiones que Jordana presentaría, sirviéndole la fórmula como medio de avanzar en sus propósitos neutralistas. En el mes de abril hubo un enfrentamiento de parecida envergadura aunque ahora motivado en otras razones: la discrepancia de criterio acerca del paso de los prisioneros aliados evadidos por la frontera pirenaica. En esta ocasión Jordana de nuevo presentó su dimisión en una larga carta a Franco en la que se quejó sobre todo de la actitud de los medios falangistas. A estas alturas, por otro lado, el Gobierno español ya tenía una representación ante las autoridades de la Francia liberada, lo que es expresivo de la voluntad neutralista del ministro de Asuntos Exteriores ${ }^{9}$.

Un buen ejemplo de cómo eran las relaciones de Franco y Jordana nos lo dan las sucesivas declaraciones que ambos hicieron durante el mes de abril de 1943. Durante la inauguración de la primera sesión de las Cortes españolas, un mes antes, Franco se había referido a la guerra mundial en un tono en que quedaba manifiesta su perplejidad ante el conflicto, que, según él, habría llegado a un "punto muerto». Un mes después, Jordana intervino en un acto destinado a conmemorar, en Barcelona, el regreso de Colón a España después de descubrir América; como había sucedido en octubre anterior la empresa americana sirvió a los gobernantes españoles como medio para desvincularlos de la situación bélica existente en Europa. Ahora, sin embargo, Jordana no sólo utilizó este argumento sino que, a partir de la defensa de los principios del catolicismo, abogó por una paz «justa y fraternal» lo que indicaba ya no sólo que no había preferencia por ninguno de los dos bandos sino que la paz era la opción de la política exterior española. Tal declaración sería impresa y repartida a la diplomacia española como la mejor expresión de la política nacional ante el conflicto ${ }^{10}$. Lo curioso del caso es que no había sido específicamente consultada a Franco y que motivó en éste

9 SUÁREZ, Franco..., III, 370.

${ }^{10} \mathrm{Ya}, 18-\mathrm{III}$ y $16-\mathrm{IV}-1943$ para los discursos de Franco y Jordana. Comunicación de este último en $A G A, A E, 3501$. 
una evolución en sus declaraciones en sentido cada vez más proclive a la neutralidad. En aquel momento estaba el dictador español realizando un periplo por Andalucía. Sus primeros discursos parecían indicar que nada había cambiado en la política exterior española: habló incluso de la no-beligerancia, de la que ya ni siquiera se hacía alusión en las declaraciones españolas del momento. Sin embargo su último discurso contuvo una afirmación, la de que "era insesato retrasar la hora de la paz", que el nuncio consideró como "desconcertante», como lo era en el contexto de las declaraciones anteriores. En su diario Jordana escribió que al final Franco había hecho «un gran discurso ratificando lo dicho por mí en Barcelona» ${ }^{11}$. Eso, sin embargo, no indicaba nada más que un leve deslizamiento en la postura del Jefe del Estado español pero ni siquiera daba seguridad de que el resto de los dirigentes políticos españoles acataran de forma decidida este cambio de postura. Jordana, por estos mismos días, en mayo de 1943, tenía graves quejas en contra de la Secretaría general del Movimiento, que había firmado, sin consultar a nadie, un acuerdo de intercambio con el Frente Alemán del Trabajo, mientras que, además, practicaba una política informativa que contrastaba decididamente con la del Ministerio de Asuntos Exteriores. "De todos los Ministerios -escribió Jordana a Arresse- es ése el único que prescinde de éste en cuestiones internacionales» ${ }^{12}$.

La mejor prueba de que, aunque con discreción, el cambio en la política del Gobierno español iba avanzado es que así lo percibían los países del Eje. Se debe tener en cuenta que en la prensa las sucesivas declaraciones de Franco en sentido progresivamente neutralista coincidían con las noticias de la derrota del Eje en África: en efecto, ese cambio de postura de Franco, que líneas atrás ha quedado descrito, apareció en la prensa al mismo tiempo que se pasaba de unas afirmaciones iniciales de que el Eje resistiría en Túnez a la definitiva derrota de alemanes e italianos en dicha región. Los alemanes desde hacía tiempo habian abandonado cualquier tipo de interés directo en la política interior española. La decisión española de no entrar en la guerra en 1941 les había irritado y se mostraron cada vez más despreciativos respecto de sus dirigentes. Sin embargo como el alineamiento de Franco con el Eje había sido muy evidente en el pasado temían que las declaraciones que ahora

1 Arriba, 2 a 13-V-1943; Cicognani, 22-V-1943 en ADSS, IV, 8; Diario de Jordana 13 V-1943.

12 Jordana 7-V-1943, AMAE, 1371/2. 
hacía invocando a la paz fueran atribuidas a un deseo propio. Cuando un nuevo embajador alemán hizo presente esta queja a Franco se encontró con que éste le respondía "que España no puede adoptar otra posición internacional que la actual, que es lo que también les convenía más a ellos". También hizo Franco alusión a la necesidad de contar con el apoyo de los sectores vaticanos y católicos, indicando asi el importante giro en su posición de política exterior ${ }^{13}$. En cuanto a los italianos difícilmente estaban en condiciones de plantear ninguna queja a España cuando su capacidad de resistencia empezaba a agotarse y parecian tener ahora motivos para lamentar no haber adoptado una posición más prudente en 1940. En este momento sólo podían pedir ayuda a una España que tampoco estaba en condiciones de prestársela; a pesar de ello, el Gobierno de Franco no tuvo inconveniente en adelantar el pago de la deuda contraída con el régimen de Mussolini durante la guerra civil. En Roma, el embajador español era ahora, desde la llegada al ministerio de Jordana, Raimundo Fernández Cuesta, un falangista de primera fila, que fue informando periódicamente a Madrid de la descomposición del régimen fascista que habría de tener una amplia recuperación sobre la evolución del franquismo respecto de la guerra mundial.

España jugó un papel de primera importancia en el convencimiento de Mussolini de que la nueva ofensiva aliada en el Mediterráneo se dirigiría hacia Cerdeña o Grecia y no hacia Sicilia, como efectivamente sucedió. Desde el mes de mayo el embajador italiano en España fue informando a Roma de que el ataque aliado era inminente y sobre todo, de las pruebas que las autoridades españolas decían tener acerca del desembarco aliado en aquella dirección errada; como se sabe, habían sido los propios servicios secretos de los aliados los que habían urdido esta superchería, conscientes que la habitual porosidad de la Administración española respecto de Italia tendría como consecuencia que ésta fuera engañada ${ }^{14}$. Así sucedió y el resultado fue que el desembarco en Sicilia, tan obvio por otra parte, sorprendió a Mussolini. A partir de este momento se inició ya el declive final del fascismo que concluiría con la destitución del Duce.

Es lógico que los acontecimientos italianos tuvieran un efecto importante tanto respecto de la política interior española como de la exterior. Se debe tener en cuenta, en primer lugar, que siempre, en la etapa de

\footnotetext{
${ }_{13}$ Memorándum 12-VI-1943, AMAE 1371/2.

14 Tusell-Garcia QueIPo de Llano, Franco y Mussolini..., 200-202.
} 
Serrano Suñer, para los dirigentes españoles el modelo había sido Italia y no Alemania y que de ello derivó, además, un mayor grado de proximidad respecto de la política internacional. Además, lo sucedido en el Mediterráneo había tenido como resultado en la política española la aparición de discrepancias en la propia clase política dirigente del régimen: un grupo de altos cargos del mismo había pedido el restablecimiento de la Monarquía, lo que mostraba un cierto paralelismo con Italia. Como respuesta indirecta, Franco reunió al Consejo Nacional del partido único $y$, en su intervención ante el mismo, atacó con dureza al «liberalismo capitalista" que, según él, "había desaparecido para siempre». Tales declaraciones (y otras semejantes) tuvieron lugar tan sólo una semana después de que las potencias que representaban esa forma de organización del Estado y la sociedad desembarcaran en Sicilia; por supuesto demostraba que la perspicacia política de Franco ante la guerra mundial era mucho menor de lo que luego aseguraron sus partidarios pero, sobre todo, ponía en evidencia que la evolución española hacia la neutralidad era mucho más lenta de lo que hubiera querido el ministro de Asuntos Exteriores español quien, como se dice en su diario, pensaba que esas últimas declaraciones de Franco "dejaron bastante que desear por tocar puntos delicados no demasiado hábil ni oportunamente» ${ }^{15}$.

Una semana más tarde se produjo el colapso del fascismo del que las autoridades españolas estuvieron prontamente informadas, pero del que, en cambio, la prensa dio cuenta tardía y discretamente. La razón de la buena información reside no sólo en los estrechos contactos existentes con los dirigentes fascistas sino en el hecho de que el propio Dino Grandi, figura de primerísima importancia en la conspiración que acabó con Mussolini, informó de lo sucedido a la embajada española. En un primer momento los conspiradores parecen haber optado por mostrar lo sucedido como una vuelta a la legalidad constitucional pero sin modificar la posición en el conflicto, pero, en realidad, querían la paz y prescindir de la alianza con Alemania. En cualquier caso dar información a los dirigentes políticos españoles tenía un especial sentido porque la neutralidad española podía cobijar contactos indirectos con los aliados. En Madrid la conmoción por lo sucedido fue inmediata. Jordana, en su diario, trató despectivamente a Ciano y dio órdenes para que se testimoniara inmediatamente «simpatía y amistad» al nuevo Gobierno Badoglio, pero el impacto no sólo se produjo respecto de la política exterior sino también en la interior en cuanto que lo sucedido en Italia parecía demostrar la

${ }^{15}$ Diario de Jordana, 17 a 23-VII-1943. 
necesidad de un cambio también en España. El ministro del Ejército inmediatamente propuso un cambio de Gobierno; por su parte, los falangistas, que obviamente habrían de ser las víctimas si ese cambio se producía, recibieron información directa de cuanto había sucedido en Roma a través de alguno de los cargos de menor rango en la Embajada. Desde luego los órganos de prensa falangista no tuvieron la menor duda a la hora de expresar su posición en estos momentos: Arriba, por ejemplo, se refirió a la "fresca y firme dignidad" y al "espíritu genial» del destituido Mussolini ${ }^{16}$. Si se tiene en cuenta que este era el diario del partido único fácilmente se percibirán los límites de la neutralidad española hasta ese momento.

Precisamente porque de esta realidad eran conscientes los embajadores aliados no dejaron de aprovechar la ocasión para presionar a Franco hacia una más efectiva neutralidad; los acontecimientos militares les daban esta oportunidad, pero, además, hay que tener en cuenta que habían aparecido en la prensa anglosajona rumores, que el régimen de Franco no podía menos de considerar como preocupantes, en relación con la supuesta ayuda prestada por británicos y norteamericanos a los exiliados republicanos. Las quejas de Hayes y Hoare, embajadores norteamericano y británico respectivamente, no se referían a la actitud del ministro de Asuntos Exteriores sino a la de otros sectores de la Administración española y se remontaban al pasado, para concluir dando por supuesto que la guerra ya estaba ganada por sus países. La posición de Franco a partir de este momento quedó definida en una conversación que tuvo con el embajador norteamericano a fines de julio. A la insistencia de Hayes en el sentido de que España hiciera una declaración de neutralidad, Franco respondió que ya era neutral "de hecho". Esbozó, además, una interpretación de la guerra mundial que sería en adelante la base de todas sus intervenciones públicas hasta el final del conflicto. La guerra mundial, según él, no era una sino tres: «España no podía ser neutral respecto de Rusia, pero lo era, en cambio, entre Alemania e Inglaterra e incluso era partidaria de las potencias europeas y de los Estados Unidos en contra de Japón" ${ }^{17}$. De acuerdo con esta nueva interpretación, que no tenía en cuenta la posición española anterior, la prensa controlada por el régimen empezó ya a hablar de la "amistad» existente entre España y esas potencias anglosajonas a las que hasta el

${ }^{16}$ Tusell-García Queipo de Llano, Franco y Mussolini..., 206-212; A. Albonico «La Spagna tra Badoglio e Mussolini (1943-1945)" en Nueva rivista Storica III-IV-1985, 217-276.

17 Conversación Hayes-Franco, 28-VII-1943, AJE N. ${ }^{\circ} 2$. 
momento habia tratado como enemigas. No puede extrañar, en esas condiciones, que tanto alemanes como italianos preguntaran a las autoridades diplomáticas españolas si este cambio de lenguaje significaba una posición nueva respecto del conflicto. En general la actitud española consistió en producir los cambios de forma lentísima, casi imperceptible, de tal manera que irritaban a los países del Eje y en cambio, no satisfacían por completo a los aliados. Este tipo de actitud era inconsistente desde todos los puntos de vista pero, al mismo tiempo, resultaba inevitable dado el hecho de que había sido la misma persona la que había hecho declaraciones entusiastas a favor del Eje y ahora se pronunciaba a favor de la neutralidad.

La posición española fue ésta precisamente y eludió aceptar una "orientación" hacia los aliados propuesta por el Duque de Alba, embajador español en Londres. Según Jordana aceptar este tipo de política supondría «meternos totalmente en su órbita como vasallos". España, escribió a Alba, estaba dispuesta a mantener una estricta neutralidad y por eso había expulsado a los italianos que desde la bahía de Algeciras se dedicaban a sabotear a la flota británica de Gibraltar. Además, añadía, la Falange ha cambiado totalmente, obedeciendo, naturalmente, a instrucciones superiores. Jordana era partidario de una política cautelosa que fuera introduciendo cambios, sin anunciarlos previamente a ninguno de los beligerantes, pero cuyo resultado fuera la neutralidad final. Así se hizo, por ejemplo, con la División Azul, cumpliendo un programa que Jordana anunció a su embajador en Londres: se trataba de relevarla primero a descansar para luego suprimirla ${ }^{18}$. Así acabó haciéndose, en efecto.

Otro momento en que se pudo percibir tanto el cambio en la política exterior española como los límites del mismo fue con ocasión del final de la situación interina abierta en Italia a la caída de Mussolini. En abierta ruptura con lo que hasta entonces había sido habitual, la España de Franco mantuvo una actitud de reserva tanto respecto de la Italia monárquica como de la fascista. Dino Grandi y Ciano pidieron al embajador español en Roma permiso para trasladarse a España indicando que su propósito era establecer contacto con los aliados para llegar a un armisticio. El primero tenía alguna posibilidad de lograrlo a través de su amistad con el embajador británico en Madrid, Hoare, pero la autorización española para la entrada se retrasó: Franco no quería de ningún modo

18 Jordana, 30-VIII-1943, AMAE, 1371/3B. 
que en España se realizara una negociación que pudiera irritar a alguno de los dos bandos y, en consecuencia, contribuyó indirectamente a que el contacto no fuera posible. A comienzos de septiembre de 1943 se produjo la rendición del Gobierno italiano presidido por Badoglio frente a los aliados y la inmediata liberación de Mussolini por parte de los alemanes. Resulta muy característico de la ambigüedad española en estos momentos el hecho de que la prensa falangista recibiera con alborozo la liberación de Mussolini mientras que Jordana aprovechara la ocasión para insistir de nuevo en la evolución hacia la neutralidad. En efecto, afortunadamente para el Ministerio de Asuntos Exteriores, no había por el momento embajador español en Roma, al haberse trasladado a España para informar de los reciente acontecimientos. Esto hizo posible que la representación diplomática española permaneciera en una situación ambigua sin reconocer ninguno de los dos Gobiernos que pronto tuvo Italia. Si grande había sido el impacto de la conspiración contra Mussolini mayor fue todavía el de lo sucedido ahora en Italia sobre la clase dirigente española. Los supremos cargos militares que habían alzado a Franco con el poder, ahora le plantearon de forma meridianamente clara la posibilidad de un relevo con la restauración de la Monarquía. El paralelismo entre el caso italiano y el español parecía obvio, pero lo sucedido fue por completo distinto: quizá porque Franco hubiera aprendido de lo sucedido en Italia, no cometió el error de reunirse con la totalidad de los protestatarios a la vez, como había hecho Mussolini, ni reveló en ningún momento la menor tentación de abandonar el poder, sino que se limitó a cambiar de nuevo a algunos de los puestos dirigentes en la cúpula militar. Durante unas semanas, sin embargo, la Embajada británica en Madrid se hizo repetido eco de los rumores de que Franco iba a ser sustituido por un directorio militar ${ }^{19}$.

El giro español hacia la neutralidad era lo suficientemente evidente como para que los alemanes trataran de reaccionar en contra de él. Fueron ellos los que solicitaron, a fines de septiembre de 1943, que Franco reconociera a la República Social italiana organizada en el Norte de Italia. También en este punto nos encontramos con un testimonio de la ambigüedad española. Jordana era claramente contrario a esta medida pero Franco parece haber estado tentado de aceptar la presión alemana. Al embajador alemán, el Jefe del Estado español le aseguró que no reconocería al Gobierno monárquico, del que decía que no tenía «ningún

19 Tusell-Garcia Queipo de Llano, Franco y Mussolini... 214-225; reacciones británicas en FO $371 / 34821$ y 34789 . 
peso moral ni político" y estaba formado por «masones y traidores», mientras que mantendría relaciones de hecho con el Gobierno que seguía las inspiraciones de Mussolini. Eso fue precisamente lo que se hizo: en Roma permaneció prácticamente cerrada la Embajada española mientras que un cónsul con sede en Milán mantenía relaciones, aunque limitadas, con las autoridades de la República Social italiana. En Madrid, finalmente, el embajador italiano se decantó hacia la Monarquía, pero hubo de enfrentarse con los propios súbditos italianos residentes en España que en su mayoría parecen haber sido partidarios de Mussolini. Además la prensa falangista mantuvo una postura claramente sesgada a favor de la República Social italiana e incluso en contra de la capacidad militar de los italianos en general sin que desde el Ministerio de Asuntos Exteriores se pudiera hacer nada para conseguir un mayor grado de imparcialidad $^{20}$.

Jordana, sin embargo, podía considerar que en el plazo de un año había conseguido, ayudado por las circunstancia, transformar la posición española respecto del conflicto. Así se lo escribió a uno de sus embajadores, que habría de ser, con el paso del tiempo, su sucesor en la cartera de Asuntos Exteriores, José Félix de Lequerica: "Las circunstancias actuales nos han llevado a mantener una neutralidad que aunque no haya aparecido en el Boletín Oficial, no ocultamos a ninguno de los beligerantes y que practicamos con la máxima escrupulosidad. Alemania se hace cargo de que sólo así podremos eludir entrar en guerra, como es firme y unánime propósito del Generalísimo y del Gobierno, por ser lo que al país conviene y totalmente desea. Este viraje, hecho con máxima suavidad, pero en forma decisiva, ha sido penoso y difícil por tener que convencer y aun someter a sectores a los que en otros tiempos, en que convino mantener otra política, se habían lanzado a favor de uno de los beligerantes en forma exaltada y hasta sectaria». En esta carta narró también Jordana a Lequerica el papel que España había podido jugar como intermediario entre Portugal y Alemania con ocasión de la cesión por la primera de estas naciones de bases aéreas a los norteamericanos. Por este procedimiento, que había exigido un desplazamiento casi secreto de Jordana para mantener conversaciones por Portugal, se había logrado a la vez moderar las pretensiones norteamericanas y disminuir la posible reacción irritada de los alemanes ${ }^{21}$.

${ }^{20}$ Diario de Jordana, 27 y 29-IX-1943; informe de Rahn en STAP, 320/106.625 y 26.

${ }^{21}$ Jordana, 21-X-1943, AMAE 1371/B. 
Sin embargo, aun siendo evidente este cambio en la posición española no evitó que en el año 1944 se produjeran nuevos conflictos nacidos ahora de la presión aliada cerca de España. En parte ésta tenia su razón de ser, nacida de la posición española ante el conflicto en la etapa anterior y también de lo nulo de los cambios en la política interior española y lo lento de los que se producian en la exterior. Franco de ninguna manera se planteó la eventualidad de un cambio en su régimen o la restauración de la Monarquía; respecto de la segunda guerra mundial seguía pensando que acabaría en un empate y no se convenció realmente de la posibilidad de una victoria aliada sino en el momento en que tuvo lugar el desembarco aliado en Normandía; mientras tanto fue hacia la neutralidad empujado por los acontecimientos, la presión de los embajadores aliados o la sugerencia de su ministro de Asuntos Exteriores. Si hubiera hecho esto último de manera más decidida o hubiera acallado por completo a la Falange hubiera encontrado menos dificultades en 1944.

La presión de los embajadores aliados comenzó a ejercerse a partir del colapso italiano. Ya entonces el embajador norteamericano se quejó de que la posición española revestía un carácter excesivamente anticomunista que estaba injustificado y que practicaba «una confianza desmedida en Alemania como escudo contra el comunismo"; España debía, por el contrario, acostumbrarse a pensar en un futuro de convivencia con la URSS ${ }^{22}$. Aparte de esta queja de carácter general, los británicos y los norteamericanos presentaron reclamaciones sobre puntos concretos de la política exterior española. A la altura de diciembre de 1943, los aliados pedían con insistencia que España redujera las exportaciones de wolframio a Alemania y que se permitiera la salida de los buques de guerra italianos que, en el momento de decidirse el armisticio por parte de este país, se habian refugiado en puertos españoles. Mientras se hacían estas reclamaciones Franco mantuvo una conversación con el embajador alemán que demuestra su renuncia a plegarse a los anglosajones: le dijo que estos últimos querían "su aniquilamiento" y que él deseaba la victoria del Eje, pero se había visto obligado a «unas pocas modificaciones» de su postura para no despertar las iras de quienes tenían en sus manos la posibilidad de que España lograra aprovisionarse en productos de primerísima necesidad ${ }^{23}$.

${ }^{22}$ AMAE 1371/6.

${ }^{23}$ La entrevista de 15-XII-1943 en FO 371/60.332. 
Probablemente los dirigentes españoles hubieran deseado responder a esta presión anglosajona en forma dilatoria cediendo lo menos posible, tal como parecen revelar las palabras de Franco al embajador alemán. Sin embargo en esta ocasión, incluso contra la propia opinión de los embajadores inglés y norteamericano, fue utilizado, por parte de los respectivos Gobiernos, un lenguaje de fuerza que revelaba ya la definitiva superioridad conseguida por los aliados en el Mediterráneo. A finales de enero de 1944 quedó suspendido el aprovisionamiento de gasolina (que procedía sobre todo de los Estados Unidos) mientras no se atendiera a las reclamaciones ya presentadas. «Si resuelve ésta ya puedo darme por satisfecho", eso escribió Jordana en su diario, mientras que lamentaba «la falta de unidad al poner en práctica nuestra política internacional», a la que culpaba de lo sucedido. Es posible que fuera así, en efecto, y que, en consecuencia la España de Franco se hubiera evitado esta presión aliada en el caso de que hubiera sabido mantener de una forma más coherente una política de inequívoca neutralidad. Como quiera que fuera, lo que hizo en este momento Jordana fue plantear la cuestión claramente al embajador alemán. Si por un lado las exigencias anglosajonas habían hecho públicas reivindicaciones que de forma espontánea hubiera podido ser resueltas, al mismo tiempo ésta era una ocasión obligada para hacer retroceder la influencia alemana en otro momento abrumadora pero de la que perduraban todavía no pocos ejemplos. Así requirió de los alemanes que dejaran de tratar de influenciar a aquellos sectores de la España franquista que les estaban más próximos y que impedian que España se mantuviera en una neutralidad estricta; al mismo tiempo insistió en la ventaja que Alemania obtendría de que España se mantuviera en esa posición. El embajador alemán acabó aceptando esa actitud e incluso prometiendo que contribuiría al aprovisionamiento español en armas ${ }^{24}$.

Entre enero y mayo de 1944 la España de Franco se debatió en la alternativa de ceder o no a la presión aliada, fundamentalmente norteamericana. Ante el embajador norteamericano, Jordana expuso que una cesión como la que su país pretendía no sólo suponía un efectivo abandono de la neutralidad sino que implicaba incluso un recorte a la soberanía nacional; él estaba, además, dispuesto a atender las peticiones aliadas en el caso de que se retirara el embargo de gasolina ${ }^{25}$. Sin embargo ésa no debía ser la postura de buena parte de la clase dirigente

${ }^{24}$ Diario de Jordana 29-I-1944; conversación Jordana-embajador alemán, 7-11-1944. AJE n. ${ }^{\circ} 3$.

${ }^{25}$ Conversación Jordana-Hayes, 15-II-1944, AJE n. ${ }^{\circ}$. 
del régimen de Franco. Cuando la cuestión fue planteada en el Consejo de Ministros el ministro español de Asuntos Exteriores se encontró con la decidida voluntad contraria a cualquier cesión de la totalidad de los ministros falangistas y con tal ausencia de calor en el apoyo por parte del propio Franco que le llevó incluso a presentar una nueva dimisión; por los mismos días los falangistas proseguían sus manifestaciones pidiendo Gibraltar español ${ }^{26}$. En cuanto a los alemanes presentaron una resistencia inicialmente muy dura a los intentos de los dirigentes españoles de limitar la exportación de wolframio, que, para ellos, era un mineral de primerísima necesidad. Tanto Jordana como el propio Franco debieron entrevistarse con el embajador Dieckhoff a quien plantearon la imperiosa necesidad de ceder ante los aliados, pues Alemania era incapaz de atender las peticiones españolas. Finalmente la decisión española, tomada en los últimos días de abril de 1944 y sólo comunicada el 2 de mayo a la prensa, tuvo como consecuencia que Alemania se desentendiera casi por completo de España, tanto en los aspectos de su política interna como externa; incluso el embajador de este país permaneció ausente durante un largo período de tiempo ${ }^{27}$.

La nota en que se dio cuenta del acuerdo a que se había llegado resulta absolutamente inconcreta en su redacción española, aunque incluye la voluntad de "estricta neutralidad». La prensa, orientada por los falangistas o censuracia por ellos, apenas si se hizo eco de lo sucedido o lo presentó sibilinamente como una cesión ante la Gran Bretaña; Jordana sólo tuvo la satisfacción de que fuera el propio cuerpo diplomático español el que, consciente de las dificultades que había tenido, se manifestara claramente a su lado. Las cesiones hechas a los aliados eran importantes, pero también inevitables y consolidaban una neutralidad realista. España se comprometió a cerrar el consulado alemán en Tánger, expulsar a determinados agentes de Eje y a retirar definitivamente sus tropas del frente Este; además liberaría a los mercantes italianos surtos en aguas españolas y sometería a arbitraje lo sucedido con los buques de guerra de aquel país y reduciría sus exportaciones de wolframio de una manera tan drástica que no podría tener eficacia estratégica sobre el destino de la guerra mundial. En realidad lo sucedido fue que Alemania, aun con muchísimas dificultades, siguió manteniendo por lo menos un cierto aprovisionamiento de wolframio español por procedimientos clandestinos que incluían la ayuda de germanófilos españoles, incluso situa-

${ }^{26}$ Diario de Jordana, 1 a 11-II-1944.

${ }^{27}$ AMAE 1371/3. 
dos en posiciones importantes en el seno de la Administración. Ha de tenerse en cuenta que en estos meses iniciales de 1944 uno de los mayores éxitos editoriales en España fue el libro de Ismael Herráiz que presentaba, bajo el título Italia fuera de combate, desde una perspectiva muy positiva para el fascismo, la caída del régimen mussoliniano.

Así se explica que las últimas semanas de Jordana en el Ministerio de Asuntos Exteriores fueran semejantes al período inmediatamente anterior: hasta el 2 de agosto, en que falleció como consecuencia de un accidente de caza, debió batallar casi incesantemente contra las presiones aliadas y, sobre todo, contra quienes, en la propia política española, tenían mayor interés en seguir las inspiraciones alemanas que las del Ministerio de Asuntos Exteriores. Su gestión, en suma, había sido la ocasión óptima para que España caminara desde la no beligerancia a la neutralidad. En el informe que el embajador británico hizo, con ocasión de su muerte, se afirma que en el fondo era anglófilo, que se entregó con todo fervor a un trabajo inagotable y que su presencia en el Ministerio de Asuntos Exteriores evitó a los aliados muchos problemas en el momento del desembarco en el Norte de África durante el cual las cosas podrían haber sido muy diferentes de haber desempeñado la cartera Serrano Súñer. A Hoare, el embajador británico, le parecía que a veces había sido débil respecto del resto de la Administración española, pero admitía que quizá eso fuera debido a la presión de los sectores falangistas ${ }^{28}$.

Es evidente que fue así y la mejor prueba se encuentra en el sucesor que Franco encontró a Jordana. José Félix de Lequerica había sido, hasta el momento de ser nombrado ministro, embajador ante el régimen de Vichy y quizá su nombramiento pudo estar influido por la necesidad de hacer desaparecer una Embajada cuya misma existencia resultaba un problema; sin embargo la razón más poderosa para nombrarle ministro fue la absoluta sumisión a la persona de Franco. Lequerica, en efecto, no se había señalado por una política neutralista antes de ser nombrado. En este sentido para los británicos, por ejemplo, su nombramiento resultó una completa decepción pues esperaban una personalidad monárquica, más o menos liberal, o aliadófila, que indicara el deseo de Franco de evolucionar en un sentido más acorde con el mundo y la inminente reordenación de Europa. Pero a estas alturas Franco ya había decidido en ningún modo poner en cuestión su mando: por muy incoherente que

${ }^{28}$ HOARE, Embajador..., 306-308 y FO 371/30.816. 
fuera repitió una y otra vez que la política exterior de su régimen había sido siempre una y la misma, sin inclinarse por ninguno de los beligerantes. Lequerica no hizo sino plegarse a los acontecimientos y vino a darse la paradoja de que, con el tiempo, sería todavía ministro en el momento en que un personaje tan importante de Vichy como era Laval, a quien conoció en su cargo diplomático como embajador, quiso refugiarse en España después de la derrota definitiva del Eje. 